\title{
PENAMPILAN REPRODUKSI KUDA BETINA PASCA PACU DI DESA PINABETENGAN RAYA KECAMATAN TOMPASO BARAT KABUPATEN MINAHASA
}

\author{
F.A. Moningka, H. Lapian, U. Paputungan*, S. Turangan \\ Fakultas Peternakan Universitas Sam Ratulangi Manado, 95115
}

\begin{abstract}
ABSTRAK
Ternak kuda merupakan jenis hewan yang istimewa diantara hewan-hewan ternak lainnya, karena bila dijual kuda dapat menghasilkan uang yang lebih tinggi tiap ekornya bila dibandingkan dengan hewan lain. Dalam upaya pengaturan pembiakan, hal-hal yang ada kaitannya dengan reproduksi harus diperhatikan agar diperoleh standar kuda pacu khas Indonesia yang disebut Kuda Pacu Indonesia (KPI). Penelitian dan observasi mengenai tampilan reproduksi (umur pertama kawin, lama siklus berahi, service per conception, foaling interval) sangat dibutuhkan agar diperoleh tingkat keberhasilan reproduksi yang tinggi. Saat ini informasi tentang penampilan reproduksi kuda betina pasca pacu di Desa Pinabetengan Raya masih sangat minim. Informasi yang diketahui baru sebatas perbedaan penanganan kuda betina khusus pacuan dan kuda betina biasa. Berdasarkan hal tersebut maka perlu dilakukan identifikasi dalam rangka mengetahui penampilan reproduksi kuda betina pasca pacu. Tujuan penelitian ini adalah untuk mengetahui penampilan reproduksi kuda betina pasca pacu di Desa Pinabetengan Raya Kecamatan Tompaso Barat. Materi yang digunakan dalam penelitian ini yaitu kuda betina bekas pacu yang ada di Desa Pinabetengan Raya sebanyak 103 ekor.
\end{abstract}

Korespondensi (corresponding Author) Email umarfapet@yahoo.com
Metode penelitian yang digunakan yaitu studi kasus dengan sumber data primer dan sekunder. Metode pengumpulan data yaitu wawancara terhadap peternak yang dipilih dengan metode purposive sampling, dengan analisis data untuk penelitian ini dilakukan secara kuantitatif deskriptif. Variabel yang diamati yaitu umur pertama kawin, lama siklus berahi, service per conception (S/C) dan foaling interval (FI) secara berurutan adalah 5,72 tahun; 21,67 hari; 1,65 kali; 11,98 bulan. Berdasarkan hasil penelitian ini dapat disimpulkan bahwa kuda betina pasca pacu di Desa Pinabetengan Raya memiliki penampilan reproduksi yang cukup baik.

Kata kunci : lama siklus berahi, service per conception, foaling rate, foaling interval

\section{ABSTRACT}

\begin{tabular}{lcrr} 
REPRODUCTION & \multicolumn{2}{r}{ PERFORMANCE } \\
OF FORMER & RACING & FEMALE \\
HORSE & AT & \multicolumn{2}{c}{ PINABETENGAN } \\
VILLAGE & WEST & TOMPASO \\
DISTRICT & OF & MINAHASA
\end{tabular}

REGENCY. Horse was the special animal to gain more money compare with any other animals. Breeding management related to reproduction of racing female horse must be taken intensively to produce a standard racing Indonesian horse called Indonesian racing horse (Kuda Pacu Indonesia, KPI). This study was conducted 
to evaluate reproduction performance of former racing female horse including first mating age, period time of estrus cycle, service per conception, foaling interval at Pinabetengan village, west Tompaso district of Minahasa regency. This village was a core area of farmer maintaining more racing horse in Minahasa regency. This study was done using purposive sampling method and focused on 103 former racing female horses as case study observation in obtaining primer data. The interview was also conducted to the owners of racing horse. Results showed that the averages of first mating age was 5.72 years, period time of estrus cycle was 21.67 days, service per conception was 1.65, and foaling interval was 11.98 months. Therefore, it can be concluded that former racing female horses at Pinabetengan village were included at good category of reproduction performance.

Key words: First mating age, estrus cycle period time, service per conception, foaling interval, Pinabetengan village

\section{PENDAHULUAN}

Ternak kuda merupakan jenis hewan yang istimewa diantara hewanhewan ternak lainnya, karena bila dijual kuda dapat menghasilkan uang yang lebih tinggi tiap ekornya bila dibandingkan dengan hewan lain. Namun dengan adanya kemajuan teknologi maka pengembangan ternak kuda yang berorientasi pada pemakaiannya sebagai alat transportasi semakin terdesak. Akan tetapi dengan adanya pertumbuhan ekonomi maka minat masyarakat pada potensi sumber daya hewani dalam memberi kepuasan batin (hobby) semakin meningkat, sehingga ternak kuda kembali diminati oleh masyarakat untuk dikembangkan dan mendapat keuntungan.

Dalam upaya pengaturan pembiakan, hal-hal yang ada kaitannya dengan reproduksi harus diperhatikan agar nanti diperoleh kuda-kuda yang memenuhi standar kuda pacu khas Indonesia yang disebut Kuda Pacu Indonesia (KPI). Sulawesi Utara adalah daerah yang mempunyai potensi yang baik dalam mengikutsertakan kuda dalam lomba pacuan kuda, sehingga kualitas dari kuda mulai diperhatikan sejak dini agar menghasilkan bibit yang lebih unggul. Untuk menghasilkan kuda dengan kualitas dan keunggulan yang diinginkan, tentu harus disertai dengan usaha-usaha yang disebut dengan seleksi dan pengaturan pembiakan serta manajemen yang baik.

Potensi yang ada di Desa Pinabetengan Raya berupa kuda pacu ini harus dikembangkan dan dilestarikan. Dalam pengambangan 
kuda pacu oleh masyarakat peternak yang ada di Desa Pinabetengan Raya sudah tidak bersifat tradisional lagi melainkan mengarah ke semi modern, peternak sudah mulai memperhatikan tatalaksana pemeliharaan, pemilihan bibit, pemberian pakan dan system perkandangan. Kuda sudah ditempatkan dalam kandang individu dengan waktu exercise yang sudah diatur sesuai jadwal oleh peternak. Walaupun demikian masyarakat peternak masih perlu mendapat pengarahan tentang tampilan reproduksi ternak kuda khususnya kuda betina pasca pacu, mengingat pemahaman mengenai tatalaksana pemeliharaan khususnya pengembangbiakkan diperoleh peternak secara turun temurun.

Masyarakat Desa Pinabetengan Raya memperoleh kuda dari warisan orang tua dan dikembangbiakan, ada juga dengan cara kongsi, menyewa betina induk sampai menghasilkan keturunan, dan dengan cara membeli. Kuda yang ada di Desa Pinabetengan Raya pada umumnya merupakan hasil upaya dari beternak sendiri dibandingkan membeli. Saat ini di Desa Pinabetengan Raya terdapat pejantan unggul yang dikirim langsung dari Australia dengan harga per satu kali kawin Rp. 1,5 juta per ekor, sehingga peternak memelihara kuda selain untuk dijadikan kuda pacu juga dijadikan kuda bibit seperti jantan pemacek. Selain pejantan unggul peternak juga memelihara kuda betina yang dijadikan induk (kuda ternak).

Desa Pinabetengan Raya memiliki 944 kepala keluarga dengan mata pencarian pada umumnya sebagai petani dan peternak. Jumlah kuda pacu yang ada di Desa Pinabetengan Raya kurang lebih 173 ekor termasuk kuda dari pengusaha atau pejabat yang khusus dipelihara di Desa Pinabetengan Raya.

Saat ini informasi tentang penampilan reproduksi kuda betina pasca pacu di Desa Pinabetengan Raya masih sangat minim. Informasi yang paling jelas diketahui baru sebatas perbedaan penanganan kuda betina khusus pacuan dan kuda betina biasa. Kuda betina khusus pacuan ditangani dengan baik mulai dari perkandangan, pakan hingga penanganan setelah pacuan. Kuda betina biasa hanya dipelihara dikebun dengan pakan seadanya. Betina biasa yang bunting hanya dibiarkan dikebun dengan penanganan kebuntingan yang biasa.

Penelitian dan observasi mengenai tampilan reproduksi (umur pertama 
kawin, lama siklus berahi, service per conception, foaling interval) sangat dibutuhkan untuk mencapai tingkat efisiensi reproduksi agar diperoleh tingkat keberhasilan reproduksi yang tinggi. Berdasarkan hal tersebut maka perlu dilakukan identifikasi dalam rangka mengetahui penampilan reproduksi kuda.

\section{METODE DAN MATERI PENELITIAN}

Penelitian ini telah dilakukan di Desa Pinabetengan Raya Kecamatan Tompaso Barat Kabupaten Minahasa pada April hingga Mei 2016. Materi penelitian yang digunakan dalam penelitian ini adalah ternak kuda pacu yang ada di Desa Pinabetengan Raya, dengan sumber data yaitu data primer dan data sekunder. Selain itu, penelitian ini juga akan menggunakan kuesioner atau daftar pertanyaan. Data primer diperoleh dari hasil pengamatan langsung (observasi) dan wawancara dengan peternak menggunakan media kuesioner. Data sekunder diperoleh dari instansi yang terkait dengan penelitian ini. Metode penelitian yang digunakan yaitu metode studi kasus. Metode studi kasus adalah pengkajian secara rinci terhadap sasaran penelitian, dan ditelaah secara mendalam sebagai suatu totalitas sesuai dengan tujuan penelitian (Aries, 2008).

\section{Teknik Pengambilan Data}

Pengambilan data dilakukan melalui observasi dan wawancara dengan menggunakan kuesioner. Wawancara dilakukan terhadap peternak yang memiliki kuda pacu, khususnya kuda pacu betina. Sampel dipilih secara purposive sampling yaitu pemilihan subyek didasarkan atas ciriciri atau sifat-sifat tertentu yang sudah diketahui sebelumnya yakni jumlah kuda pacu betina. Selain itu, pengambilan sampel dilakukan dengan sengaja untuk mencapai suatu tujuan tertentu, dalam hal ini penampilan reproduksi ternak. Jumlah sampel yang digunakan yaitu 103 ekor

\section{Analisis Data}

Analisis data dilakukan secara kuantitatif deskriptif untuk menggambarkan penampilan reproduksi kuda betina pasca pacu di Desa Pinabetengan Raya. Variabel yang diamati meliputi umur pertama kawin, lama siklus berahi, service per conception dan foaling interval. 


\section{HASIL DAN PEMBAHASAN}

\section{Umur Pertama Kawin}

Berdasarkan hasil penelitian, dapat disusun data yang disajikan dalam Tabel 1. Rataan umur pertama kawin kuda pacu sesuai dengan penelitian yaitu 5,72 tahun. Umur ini melebihi umur pertama kawin yang dijadikan acuan. Blackley dan Blade (1991) mengemukakan bahwa kuda betina sebaiknya dikawinkan pada umur 2 tahun atau bahkan akan lebih baik setelah mencapai umur 3 tahun.

Berdasarkan penelitian yang dilakukan, kuda digunakan sebagai kuda pacu pada umur 2-5 tahun. Setelah tidak digunakan sebagai ternak pacu, kuda betina baru mulai dikawinkan. Inilah yang menjadi alasan umur pertama kawin kuda di Desa
Pinabetengan Raya diatas rata-rata umur acuan yang digunakan.

Penelitian tentang performans kuda juga dilakukan oleh Setyobudi et.al (2009) di Kabupaten Bantul DIY. Dalam penelitian tersebut diperoleh rataan umur pertama kawin yaitu 2,62 tahun. Perbedaan ini diduga karena kuda di Kabupaten Bantul hanya digunakan sebagai kuda kerja untuk menarik andong. Penelitian lainnya dilakukan oleh Hendri et.al (2012) di Kota Payakumbuh. Dalam penelitian tersebut, diperoleh kisaran umur pertama kawin untuk kuda keturunan thoroghbred yaitu 3,11 - 5,33 tahun. Umur tersebut mirip dengan hasil penelitian yang dilakukan karena jenis kuda yang sama dan diduga digunakan untuk keperluan yang sama.

Tabel 1. Hasil Perhitungan Umur Pertama Kawin, Lama Siklus Berahi, Service per Conception, dan Foaling Interval pada Sampel Betina Pasca Pacu di Desa Pinabetengan Raya Kecamatan Tompaso Barat.

\begin{tabular}{clc}
\hline No & \multicolumn{1}{c}{ Pokok Pengamatan } & Rataan \\
\hline 1 & Sampel Betina Pasca Pacu (Ekor) & 103 \\
2 & Umur Pertama Kawin (Tahun) & 5,72 \\
3 & Lama Siklus Berahi (Hari) & 21,67 \\
4 & Service per Conception (Kali) & 1,65 \\
5 & Foaling Interval (Bulan) & 11,98 \\
\hline Sumber : Hasil Olah Data 2016
\end{tabular}

\section{Lama Siklus Berahi}


Panjang siklus berahi bervariasi dalam hubungannya dengan factorfaktor eksternal maupun internal (Hafez, 1993). Panjang siklus berahi pada kuda berlangsung 22 hari dengan panjang fase estrus 5-7 hari (Aurich, 2011). Lama siklus berahi dalam penelitian ini yaitu 21-30 hari dengan rataan 21,67 hari. Siklus berahi kuda yang tidak menyusui hasil penelitian Heidler, et.al. (2004) yaitu 22,8 $\pm 1,4$ hari. Jika dibandingkan, kedua hasil tersebut tidak jauh berbeda dan masih berada pada kategori siklus berahi kuda normal. Berdasarkan penelitian, juga ditemukan siklus berahi yang mencapai 30 hari. Durasi siklus berahi yang cukup panjang ini merupakan siklus berahi2 ekor kuda betina dengan umur tua. Hal ini sesuai dengan pendapat Ginther, et.al. (2008) yang menyatakan bahwa kuda tua memiliki interval siklus berahi yang dapat lebih lama karena tingkat pertumbuhan folikel dominan lebih lambat.

\section{Service per Conception (S/C)}

Service per conception atau jumlah perkawinan yang menghasilkan kebuntingan pada penelitian ini yaitu 1,65. Hasil ini cukup baik karena berada pada kisaran ideal. S/C ideal menurut Hardjopranjoto (1995) yaitu 1-2 kali.
Tinggi rendahnya nilai $\mathrm{S} / \mathrm{C}$ ini berbanding terbalik dengan fertilitas ternak. Semakin tinggi nilai S/C menunjukkan tingkat fertilitas yang semakin rendah. Sebaliknya, semakin rendah nilai $\mathrm{S} / \mathrm{C}$ menunjukkan tingkat fertilitas yang tinggi.

Berdasarkan hasil penelitian yang dilakukan Pusung (1997) di Kecamatan Tompaso Barat Kabupaten Minahasa, menyatakan bahwa rata-rata S/C kuda pacu betina yaitu 1,98 kali. Hasil ini sesuai dengan hasil penelitian yang dilakukan, hal ini diduga karena adanya kesamaan jenis ternak, dan lokasi penelitian. Penelitian yang dilakukan Setyobudi et.al (2009) di Bantul, Jogjakarta memperoleh rataan nilai yang cukup tinggi yaitu $2,85 \pm 0,81$ kali. Hasil ini kurang baik karena S/C yang didapat masih jauh dari S/C ideal. Perbedaan ini diduga karena tujuan dari penggunaan kuda yang digunakan sebagai kuda kerja, serta jenis kuda yang berbeda.

\section{Foaling Interval (FI)}

Foaling interval atau jarak beranak merupakan jarak antara kelahiran terakhir dengan kelahiran sebelumnya. Foaling interval dipengaruhi oleh besarnya days open atau periode waktu beranak hingga 
terjadinya konsepsi, sehingga foaling interval dapat diperbaiki dengan perbaikan days open dari ternak tersebut. Dalam penelitian ini diperoleh kisaran 11-12 bulan atau rata-rata 11,98 bulan (428 hari). Berdasarkan hasil penelitian yang dilakukan oleh Setyobudi et.al (2009) dipeoleh rataan $16,21 \pm 1,41$ serta 490,18 hari seperti yang disampaikan oleh Taveira dan Mota (2007). Foaling interval ternak kuda yang ideal berkisar kurang lebih 15 bulan atau 450 hari (Blakely dan Blade, 1991). Hasil penelitian di Pinabetengan Raya jika dibandingkan

\section{DAFTAR PUSTAKA}

Aries, K. 2008. Metode Penelitian. Bumi Aksara. Jakarta.

Arif Setyobudi. Kustono, dan Diah Tri Widayati. 2009. Kinerja Reproduksi Ternak Kuda Kerja Di Kabupaten Bantul, Daerah Istimewa Yogyakarta. Fakultas Peternakan. Universitas Gadjah Mada. Bulaksumur. Yogyakarta. Buletin Peternakan Vol. 33 (3): 148-153.

Aurich C. 2011. Reproductive cycles of horses. Anim. Reprod. Sci. 124: 220-228.

Blakely, J. dan D.H. Blade, 1991. Ilmu Peternakan. Gadjah Mada UniversityPress, Yogyakarta.

Ginther et. al. 2008. Dynamics of the equine pre-ovulatory follicle and dengan hasil penelitian tersebut dan nilai FI ideal bahkan lebih baik.

\section{KESIMPULAN}

Berdasarkan penelitian yang dilakukan di Desa Pinabetengan Raya diperoleh bahwa rataan umur awal kawin kuda betina pasca pacu yaitu 5,72 tahun, lama siklus berahi 21,67 hari, service per conception 1,65 kali dan foaling interval 11,98 bulan. Hal ini menunjukkan bahwa kuda betina pasca pacu di Desa Pinabetengan Raya memiliki penampilan reproduksi yang cukup baik.

periovulatory hormones: what's new? Journal of Equine Veterinary Science 28: 454-460.

Hafez ESE, editor: 1993. Reproduction in Farm Animals. Ed ke-6. Philadelphia: Lea \& Febiger.

Hardjopranjoto, H.S. 1995. Ilmu Kemajiran Pada Ternak. Airlangga University Press, Surabaya. $P p$ : 46-47, 175-184.

Heidler et. al. 2004. Body weight of mares and foals, estrous cycles and plasma glucose concentration in lactating and nonlactating Lipizzaner mares. Theriogenology 61:883-893.

Hendri, et. al. 2012. Perbandingan Performans Reproduksi Kuda Lokal dan Turunan Thoroughbred di Kota Payakumbuh. Fakultas Peter- 
nakan. Universitas Andalas. Padang Jurnal Peternakan Indonesia. Vol. 14 (3): 441-446.

Hintz, R.L. 1980. Genetic of performance in the horse. Journal of Animal Science, 51: 582-594.

Taveira, dan da Mota. 2007. Genetic and quantitative evaluation of breeding traits in thoroughbred mares. REDVET. Revista electrónica de Veterinaria 169575042007 Volumen VIII Número 5, Brazil.

Wiliams, C.A., D.S. Kronfeld, T.M. Hess, K.E. Saker, J.N. Waldron, K.M. Crandell, R.M. Hoffman, and P.A. Harris. 2004. Anioxidant supplemen and subsequent oxidative stress of horses during an $80-\mathrm{km}$ endurance race. Journal of Animal Science, 82:588-594. 
Jurnal Zootek (“Zootek” Journal ) Vol. 36 No. 2 : 439-446 (Juli 2016)

ISSN 0852 $-2626$ 